\title{
Interactions between endothelial cells and electrospun methacrylic terpolymer fibers for engineered vascular replacements
}

\author{
A. N. Veleva ${ }^{1}$, D. E. Heath ${ }^{2}$, J. K. Johnson ${ }^{3}$, J. Nam $^{3}$, C. Patterson ${ }^{4,5,6,7}$, J. J. Lannutti ${ }^{3}$, and \\ S. L. Cooper ${ }^{2}$ \\ ${ }^{1}$ Department of Chemical and Biomolecular Engineering, NCSU, Raleigh, North Carolina 27695 \\ 2Department of Chemical and Biomolecular Engineering, OSU, Columbus, Ohio 43210 \\ ${ }^{3}$ Department of Materials Science and Engineering, OSU, Columbus, Ohio 43210 \\ ${ }^{4}$ Carolina Cardiovascular Biology Center, UNC, Chapel Hill, North Carolina 27599 \\ ${ }^{5}$ Department of Medicine, UNC, Chapel Hill, North Carolina 27599 \\ ${ }^{6}$ Department of Pharmacology, UNC, Chapel Hill, North Carolina 27599 \\ ${ }^{7}$ Department of Cell and Developmental Biology, UNC, Chapel Hill, North Carolina 27599
}

\begin{abstract}
A compliant terpolymer made of hexylmethacrylate (HMA), methylmethacrylate (MMA), and methacrylic acid (MAA) intended for use in small diameter vascular graft applications has been developed. The mechanical properties and in vitro biostability of this terpolymer have been previously characterized. The goal of this investigation was to examine the interactions between endothelial cells and the new terpolymer and to evaluate endothelial cell function. Electrospinning was used to produce both oriented and random terpolymer fiber scaffolds. Smooth solution cast films and tissue culture polystyrene were used as negative and positive controls, respectively. Human blood outgrowth endothelial cells and human umbilical vein endothelial cells were incubated with the test and control samples and characterized with respect to initial cell attachment, proliferation, viability, and maintenance of the endothelial cell phenotype. It was found that the terpolymer is cytocompatible allowing endothelial cell growth, with random fibers being more effective in promoting enhanced cellular activities than oriented fibers. In addition, endothelial cells cultured on these substrates appeared to maintain their phenotype. The results from this study demonstrate that electrospun HMA:MMA:MAA terpolymer has the potential to be used successfully in fabricating small diameter blood vessel replacements.
\end{abstract}

\section{Keywords}

methacrylic terpolymers; biocompatibility; electrospinning; endothelial cells; engineered vascular grafts 


\section{INTRODUCTION}

Many blood-contacting medical devices are compromised by excessive thrombus formation at the blood-material interface. ${ }^{1}$ A healthy endothelial layer is the only fully blood compatible surface that completely avoids thrombus development. However, a confluent and functioning endothelial cell layer has yet to be achieved on vascular grafts. Clearly, new synthetic material formulations demonstrating improved blood- and cyto-compatibility are needed. The objective of this investigation was to evaluate the interactions between endothelial cells and methacrylate-based terpolymer fiber scaffolds that could be used in small diameter vascular graft applications.

It has been shown that vascular grafts supporting a layer of adherent endothelial cells have greater resistance to thrombosis and graft occlusion. ${ }^{2}$ The natural blood vessels in the human body contain a lining of endothelial cells on the luminal surface that actively resists thrombus formation by releasing prostacyclin, nitric oxide, heparin sulfate, and other anticoagulants. ${ }^{3}$ However, clinically employed vascular grafts do not spontaneously endothelialize; endothelial cells typically cover only a small percentage of the luminal surface, leaving a portion of the graft without a complete endothelial cell layer. ${ }^{4}$ For this reason, methods of promoting endothelial cell growth and adhesion on vascular grafts are an active area of investigation.

Considerable effort has been directed toward developing small diameter blood vessel replacements with chemistries and/or architectures that resemble the corresponding natural extracellular matrix (ECM) ${ }^{5-9}$ Such approaches attempt to provide cells with structural signals leading to cellular architectures that more faithfully recapitulate in vivo morphology and function. Electrospinning is an ideal method for producing a network of fine fibers that mimic the in vivo ECM. ${ }^{10-15}$ The fibrous structures produced by the electrospinning process have a high surface area to volume ratio providing enhanced cell response and potentially a higher cell density per unit volume compared to other structures. Over the past decade, many natural and synthetic compositions have been electrospun in targeting specific biomedical applications. ${ }^{16-21}$

We have recently developed compliant methacrylic terpolymers made of hexylmethacrylate (HMA), methylmethacrylate (MMA), and methacrylic acid (MAA) as possible replacements for polyethylene terephthalate (PET, Dacron) and expanded polytetrafluoroethylene (ePTFE) in small diameter vascular graft applications. ${ }^{22-24}$ Our materials are designed to be biostable, in contrast to other approaches of tissue engineering where biodegradable scaffolds are employed. Biostable, small diameter vascular grafts should avoid the problems of diameter growth and aneurysm formation over long implant periods. ${ }^{1}$ An additional advantage is the ease of modification of the mechanical properties by manipulating the glass transition temperature, $T_{\mathrm{g}}$, allowing for "tuning" of the overall compliance. ${ }^{22,25}$ In this work, we utilized electrospinning to produce a morphologically relevant scaffold composed of methacrylic terpolymer fibers. We hypothesize that topographies produced by electrospinning will lead to enhancement of endothelial cell-terpolymer material interactions and will improve the surface cyto- and biocompatibility, because the architecture is more analogous to the ECM of the native arterial wall. Smooth, solution cast terpolymer films and tissue culture polystyrene (TCPS) surfaces were used as negative and positive controls, respectively. The cellular response - attachment, proliferation, viability, and phenotypic expression-of human blood outgrowth endothelial cells (HBOEC) and human umbilical vein endothelial cells (HUVEC) was evaluated. 


\section{MATERIALS AND METHODS}

\section{Synthesis of methacrylic terpolymer}

The synthesis of the methacrylic terpolymer was carried out by a free radical polymerization reaction described previously. ${ }^{22-24}$ Briefly, the monomers used in the reaction were $n$-hexyl methacrylate (HMA) (Alfa Aesar, Ward Hill, MA), methyl methacrylate (MMA) (ACROS Organics, Pittsburgh, PA), and MAA (ACROS Organics). The polymerization reaction was performed in dimethylformamide (DMF) (Sigma-Aldrich, Milwakee, WI) using 2,2azobisiso-butyronitrile (AIBN) (Sigma-Aldrich) as the initiator. The molar ratios of the monomers in the feed were 20 mol \% HMA, 78 mol \% MMA, and 2 mol \% MAA. The reaction was carried out overnight at $55-60^{\circ} \mathrm{C}$. After the reaction was stopped, the solvent was evaporated and the resulting polymer was soaked for $24 \mathrm{~h}$ in 50:50 v/v methanol:water mixture to remove unreacted reagents. The purified terpolymer was dried in a vacuum oven at $55^{\circ} \mathrm{C}$ for $48 \mathrm{~h}$ and then stored in a desiccator. Terpolymer molecular weight was determined by gel permeation chromatography.

\section{Electrospinning of terpolymer fibers}

The terpolymer solution was dissolved in an equimolar mixture of acetone and ether to produce a $13 \mathrm{w} / \mathrm{v} \%$ solution. This was then passed through a 22-gauge needle at a rate of 16 $\mathrm{mL} / \mathrm{h}$ using a syringe pump. A collector plate was placed $16 \mathrm{~cm}$ from the needle. A voltage difference of $22 \mathrm{kV}$ was applied to the needle. These conditions lead to the establishment of a stable Taylor Cone in which the polymer solution was converted into fiber by the applied voltage and deposited on the collector in the form of a nonwoven random terpolymer mat. To form oriented terpolymer mats, fibers were electrospun onto a rotating collector. A 70 $\mathrm{cm}$ diameter wheel rotating at $350 \mathrm{rpm}$ was used. Fibers were electrospun onto the circumferential edge of the collector moving at a linear velocity of $13 \mathrm{~m} / \mathrm{s}$. To improve deposition, a dual source method was used: a positive $12 \mathrm{kV}$ potential was applied to the needle and a negative $10 \mathrm{kV}$ potential was applied to the collector.

The fiber morphology was examined using scanning electron microscopy (Philips XL30 ESEM FEG). Samples were plasma coated with $10 \mathrm{~nm}$ layer of osmium and analyzed in ultrahigh-resolution mode with a $10 \mathrm{kV}$ accelerating voltage. Fiber diameter and pore area (area of the pore polygon) of the terpolymer meshes were measured from the scanning electron microscope images by measuring 60 randomly chosen fibers; porosity measurements were performed using Image $\mathbf{J}$ image analysis software (Image J, Bethesda, $\mathrm{MD})$.

\section{Preparation of terpolymer films}

As a control, uniform thin films of the terpolymer were generated by a simple dip coating method. The polymer was dissolved at a concentration of $5 \mathrm{w} / \mathrm{v} \%$ in acetone/ether (1:1) mixed solvent. The resulting solution was dip coated onto 18-mm-glass cover slips (Fisher Scientific, Fair Lawn, NJ) at room temperature. Following solvent evaporation, the terpolymer coated cover slips (referred as terpolymer solution cast films) were placed in a vacuum oven at $55-60^{\circ} \mathrm{C}$ for $24 \mathrm{~h}$ to remove any remaining solvent.

\section{Cell culture}

The use of human material described in this study was approved by the responsible ethics committee. HBOEC were isolated from peripheral blood as described in our previous report. ${ }^{26,27}$ Fresh blood was collected from healthy volunteer donors by venipuncture and anticoagulated with buffered sodium citrate. Buffy coat mononuclear cells were obtained by density gradient centrifugation method using Histopaque 1077 (Sigma - Aldrich). The cells were washed in PBS three times at $400 \mathrm{~g}$ for $10 \mathrm{~min}$ before culturing. Buffy coat 
mononuclear cells from $100 \mathrm{~mL}$ peripheral blood were resuspended in EGM-2 medium (endothelial cell growth medium 2; Cambrex Bioscience, Walkersville, MD) and placed into one well of a six-well plate coated with type 1 collagen (BD Biosciences, Bedford, MA). The plate was incubated at $37^{\circ} \mathrm{C}$ in a humidified environment with $5 \% \mathrm{CO}_{2}$. Nonadherent cells were removed after $48 \mathrm{~h}$ and every second day thereafter. Colonies with cobblestone morphology appeared following 3-4 weeks in culture. These cells were cultured until they formed larger colonies.

HUVEC were obtained from Cambrex Bioscience. The cells were cultured in endothelial cell basal medium-2 supplemented with growth factors and fetal bovine serum (EGM-2 bullet kit, Cambrex Bioscience). Cultures were incubated in a humidified environment with $5 \% \mathrm{CO}_{2}$ at $37^{\circ} \mathrm{C}$. The culture medium was changed every 2 days. HUVEC passages 4 through 8 were used.

\section{Assessment of cell adhesion}

Adhesion behavior of HBOEC and HUVEC on different substrata was evaluated by cell counting. Solution cast films, oriented and random fiber substrates were placed in a 12-well cell culture plate. All surfaces were sterilized in 70\% ethanol/30\% water solution for $15 \mathrm{~min}$ followed by three washes in PBS. Samples were equilibrated overnight in sterile PBS at $37^{\circ} \mathrm{C}$. HBOEC and HUVEC were detached with $0.05 \%$ trypsin-EDTA (Mediatech, Herndon, VA) and their number counted using a hemocytometer. Cell concentrations were adjusted with medium to the corresponding plating densities. HBOEC and HUVEC were seeded separately on the sterilized surfaces at plating densities of 3000,6000, and 12,000 cells $/ \mathrm{cm}^{2}$, respectively. TCPS wells served as positive control surfaces. After $6 \mathrm{~h}$, the incubation medium was aspirated and the cells were washed with PBS, fixed with $3.7 \%$ formaldehyde, and incubated with $0.01 \%$ nuclear stain DAPI (Sigma-Aldrich) in PBS. Experiments were done in triplicate and repeated three times. The stained cells-terpolymer constructs were examined using fluorescence microscopy (Olympus, Center Valley, PA), and images of 15 randomly selected locations were recorded. Cells were enumerated using Image $\mathbf{J}$ software on the basis of threshold analysis.

\section{Assessment of cell proliferation}

For the proliferation studies, samples were sterilized as described above. HBOEC and HUVEC were seeded separately on TCPS wells, solution cast films, oriented and random terpolymer fibers, respectively at a plating density of $6000 \mathrm{cells} / \mathrm{cm}^{2}$. The cells were allowed to proliferate for 3, 6, and 9 days after which proliferation was determined by cell counting as described for the adhesion studies. Experiments were done in triplicate and repeated three times. Fluorescence images were again taken from 15 randomly chosen locations for each condition. Cell densities were determined using Image $\mathbf{J}$ software as before.

\section{Assessment of cell viability and metabolism}

Cell viability and metabolism were measured using Cell Counting Kit-8 (Dojindo Molecular Technologies, Gaithersburg, MD). This is a colorimetric assay for quantification of cell viability and metabolism and is based on the cleavage of a tetrasolium salt (WST-8) by mitochondrial dehydrogenises in viable cells. Increased enzyme activity leads to an increase in the amount of formazan dye which is measured with a spectrophotometer. After a 9 dayincubation period, the cell culture medium was aspirated and fresh medium was added along with CCK-8 reagent (10:1 ratio). Cell culture medium and CCK-8 reagent were added to three wells without cells to serve as a background control. Plates were then incubated for an additional $3 \mathrm{~h}$ at $37^{\circ} \mathrm{C}$. After incubation, $100 \mu \mathrm{L}$ of solution from each well was transferred into a separate 96-well plate, where the absorbance of the samples against a background 
control was measured at a wavelength of $450 \mathrm{~nm}$ on a Wallac-VICTOR ${ }^{3 \mathrm{TM}}$ microplate reader (Perkin-Elmer, Wellesley, MA).

\section{Immunohistochemical staining for von Willebrand factor}

After 9 days of culture, endothelial cells were fixed with 3.7\% paraformaldehyde/PBS solution. Then cells were permeabilized with $0.2 \%$ Triton X-100 in PBS. Rabbit antihuman vWF primary antibody (Dako Cytomation, Carpinteria, CA) diluted 1:400 in PBS/0.1\% BSA was added and incubated for $60 \mathrm{~min}$ at room temperature. After two PBS washes, goat anti-rabbit 488 AlexaFluor-conjugated secondary antibody (Molecular Probes, Eugene, OR) at a 1:200 dilution was added and incubated for $30 \mathrm{~min}$ at room temperature. The samples were rinsed twice with PBS. Finally, the cells were counterstained with DAPI (SigmaAldrich) for $5 \mathrm{~min}$ at room temperature to visualize the cell nucleus. The immunostained cellular construct samples were mounted on microscope slides with Prolong Gold reagent (Molecular Probes) and observed under a fluorescence microscope.

\section{Data analysis and statistical methods}

All statistical comparisons were done by univariate analysis of variance (ANOVA) using SPSS software (Ver. 14, Chicago, Il) followed by Turkey's honest significant difference (HSD) analysis. The data were presented as mean \pm standard deviation (SD). Differences were considered statistically significant when $p<0.05$.

\section{RESULTS AND DISCUSSION}

\section{Terpolymer synthesis and electrospinning of terpolymer fibers}

Random terpolymer was synthesized via free radical polymerization reaction using HMA, MMA, and MAA. The large pendant group of the HMA monomer allows "tuning" of the compliance of the terpolymer through its contribution to lowering the $T_{\mathrm{g}}$ of the polymer. ${ }^{22,25}$ MMA and MAA provide durability and ionic functionality for further downstream chemical modifications, respectively. ${ }^{24}$ The monomer ratios in the feed-20 mol \% HMA, 78 mol \% MMA, and 2 mol \% MAA — were chosen based on preliminary electrospinning experiments demonstrating that 20:78:2 terpolymer composition can be fabricated into stable architectures with well-defined topographies including controlled fiber diameter, orientation, and pore size. The number-average molecular weight of the synthesized terpolymer was $223 \pm 15 \mathrm{kDa}$ based on GPC measurements. The electrospinning process did not result in detectable changes in terpolymer molecular weight.

Figure 1 shows successfully electrospun HMA: MMA:MAA terpolymer with a composition $20 \mathrm{~mol} \%: 78 \mathrm{~mol} \%: 2 \mathrm{~mol} \%$ from the $13 \mathrm{w} / \mathrm{v} \%$ terpolymer acetone-ether solution. Both acetone and ether are volatile organic solvents. This property promotes solvent evaporation under atmospheric conditions and the deposition of fibers in a nearly dry state. Solvent volatility may be a factor in determining individual fiber morphology. Reportedly, use of the mixed solvents we employ reduces beading artifacts and spindle-like formations by enhancing solution dielectric constant and conductivity. ${ }^{10,11}$ In the present study, we produced bead-free monolithic fiber having a fairly regular diameter. Electrospinning of the terpolymer solution onto a stationary collector resulted in random fiber networks [Fig. 1(B,D)]. In contrast, deposition onto a rotating collector yielded oriented fiber as visible in Figure 1(A,C). Although many system and process variables influence fiber topography, the velocity of the collection surface is critical to orient the fibers. Our results show that a collector velocity of $13 \mathrm{~m} / \mathrm{s}$ induces highly anisotropic polymer networks.

Figure 2 gives the results from quantitative analysis of oriented and random fiber diameter along with analysis of the pore area distribution. Fiber diameters in the submicron range are 
present in both the oriented and random topographies. Oriented fibers exhibit more uniform diameter distribution. Further, the diameter of the oriented fibers is smaller than that of the random fibers. The decrease in oriented fiber diameter compared to that of random fibers may result from an extensional force applied by the rotating collector. The bottom panel in Figure 2 reveals the pore area distribution for the oriented and random fiber architectures defined as the area of the pore polygon. The results suggest that, not surprisingly, fiber packing becomes more efficient during deposition on the rotating collector. This finding is consistent with the induction of increased fiber orientation. Our data presented in Figures 1 and 2 also underscore the potential role of electrospun tissue engineering scaffold geometry in modulating surface interactions with endothelial cells. Cells on such surfaces are sensitive to (i) the surface topography of the fibers themselves, and (ii) and the overall topography of the electrospun fiber networks. By tailoring scaffold surface morphology it may be possible to provide contact guidance signals to regulate cell function and more closely mimic the material properties of native structures.

\section{Evaluation of endothelial cell response}

The adhesion profiles of HBOEC and HUVEC seeded on solution cast, oriented and random terpolymer fibers as well as on TCPS surfaces are shown in Figure 3 as a function of plating density. HBOEC and HUVEC attached to all substrates in a dose-dependent manner over 6$\mathrm{h}$ period. Furthermore, the adhesion of both cell types is influenced by the topography. More specifically, random terpolymer fibers promote significantly greater adhesion of HBOEC and HUVEC compared to both oriented fibers and smooth solution cast films. HBOEC cultured on TCPS surfaces attach and proliferate for all plating densities, approaching a twofold increase in cell population during the 6-h incubation period. The more rapid response of HBOEC cultured on TCPS is not surprising as these endothelial cells are derived from endothelial progenitors circulating in peripheral blood and thus retain high proliferative activity. ${ }^{27,28}$ Overall HBOEC adhesion to terpolymer surfaces was greater than HUVEC adhesion. However, the attachment of both cell types is dependent on substrate morphology. Not surprisingly, our results are consistent with reports providing evidence that surface topography influences the adhesion of many different cell types-endothelial cells, ${ }^{8,18,20}$ smooth muscle cells, ${ }^{19}$ COS-7 cells, ${ }^{16}$ fibroblasts,,${ }^{17}$ chondrocytes, ${ }^{17,21}$ etc.

The molecular mechanism(s) behind the observed surface topographic dependence of cell adhesion remains to be elucidated. It is generally believed that the adhesion of cells to synthetic materials is mediated by absorbed serum proteins. ${ }^{29}$ Cells in their natural environment are anchored by receptor-ligand interactions to proteins in the ECM. Cell attachment to substrate surfaces in vitro occurs by adhesion proteins contained in the serumsupplemented cell culture medium. Cell binding to ligands presented by serum proteins and ECM components is primarily mediated by integrins - transmembrane cellular receptors composed of $\alpha$ and $\beta$ subunits. ${ }^{30}$ Upon ligand binding, integrins cluster together and organize into focal adhesion complexes that contain structural and signaling proteins. The focal adhesions are connected downstream with cytoskeletal elements that transmit signals used by the cells for control over various cell processes such as migration, survival, proliferation, and differentiation. ${ }^{31}$ In the context of this experiment, however, the scale of protein adsorption is much smaller than that of the fiber topography. In addition, the surface chemistry of the two nanofiber structures is identical eliminating net differences in total adsorbed protein or its conformation as a variable.

To examine the effect of topography on proliferation, the cell number was assessed on days 3,6 , and 9. The proliferation kinetics of HBOEC and HUVEC on solution cast terpolymer films, oriented fibers, random fibers, and control TCPS surfaces is presented in Figure 4 and demonstrates that proliferation occurred on all substrates. HBOEC on all topographies exhibited a significant increase in cell number between days 3 and 6 while HUVEC 
proliferation was delayed and cell numbers increased significantly between days 6 and 9 . Both cell types proliferated on TCPS surfaces better than on the terpolymer surfaces and reached confluence by day 9 . True confluence has not been reached in any of the terpolymer surfaces. One possible reason for this observation is that the pore sizes of the electrospun constructs (see Figs. 1 and 2) may be too large to support the formation of an endothelial monolayer. However, HUVEC cultured on oriented and random fiber surfaces exhibited significantly higher proliferation than on smooth solution cast films. The lower HUVEC density on solution cast films can be rationalized by examining the relatively low initial seeding density $\left(6000 \mathrm{cells} / \mathrm{cm}^{2}\right)$ that produced lower cell attachment values (see Fig. 3, bottom panel) and slower proliferation rates. The smooth terpolymer films are not cytotoxic to HUVEC as demonstrated in Figure 5.

The data presented in Figure 4 also reveal significant increase in cell populations on random fibers compared to oriented and smooth terpolymer surfaces. It has been widely reported that enhancement of cellular responses can be achieved by varying the surface topography. ${ }^{13-21}$ The attachment of HBOEC and HUVEC to random fibers induces increased number of cells to enter the $\mathrm{S}$ phase of the cell cycle resulting in the observed higher proliferation rates. Most likely this occurs through enhanced interaction of soluble mediators, adhesive ligands, and cell surface receptors between cells on random (versus oriented) fibers as these are more likely to intersect and allow direct cell-cell contact.

HBOEC and HUVEC viability and metabolic activity at day 9 on the test and control surfaces measured by mitochondrial activity assay (CCK-8 assay) are presented in Figure 5. The viability and metabolic activity results are in agreement with the findings from the proliferation experiments. Metabolic activity for both cell types cultured on random terpolymer fiber supports is statistically comparable to TCPS surfaces. Furthermore, HBOEC seeded on smooth surfaces and oriented terpolymer fibers maintains metabolic activity statistically equivalent to HBOEC cultured on random fibers and TCPS. Figures 3-5 clearly show differences in HBOEC and HUVEC interactions with the underlying substrates that lead to differences in cellular function. We are currently characterizing differentially the cell surface molecular profiles for both cell types using subtractive phage displayed peptide library protocol to identify ligands that bind specifically to HBOEC cell surface receptors. ${ }^{26,27}$

In addition to promoting cell attachment and proliferation, a successful scaffolding material must foster the phenotypic differentiation and stability of the adherent cells. The differentiation status of HBOEC and HUVEC in contact with the terpolymer was investigated by expression and localization studies of von Willebrand factor antigen (Factor VIII). As shown in Figure 6, HBOEC cultured on smooth and textured terpolymer surfaces for 9 days highly express von Willebrand factor (green color). Similar observations were made for HUVEC (data not shown). These results indicate that the cells grown on the methacrylic terpolymers maintain their endothelial cell phenotype during the in vitro culture comparably to cells grown on control TCPS substrates.

Interestingly, on the oriented fiber surfaces, von Willebrand factor is localized within a highly anisotropic cytoplasmic region. Notably, not only the cell cytoplasm is elongated but also the cell nucleus (blue color). It is likely that cell alignment might be influenced by the aligned topography of the terpolymer fiber surface. Ma et al. ${ }^{18}$ reported orientation of human aortic endothelial cells cultured on aligned poly(caprolactone) fibers. Also aligned poly(L-lactide- $c o-\varepsilon$-caprolactone) copolymer nanofiber scaffolds oriented smooth muscle cells ${ }^{19}$ and endothelial cells ${ }^{20}$ along the direction of the fibers. The ability of scaffold topography to control the orientation of cells is meaningful for engineered vascular replacements. Shear caused by the blood flow in vivo induces endothelial cell orientation 
along the blood flow which may increase the ability of endothelial cells to resist shear stress. ${ }^{32}$ Therefore, if one can develop a scaffold architecture mimicking that of the native artery, the alignment of endothelial cells and thus increased initial shear stress resistance can be induced before implantation leading to effective vascular tissue regeneration. Further work needs to be performed to ensure that this is the case; for example endothelial cellterpolymer interactions and endothelial cell coverage after exposure to physiological shear stress using an in vitro flow system will be evaluated.

\section{CONCLUSIONS}

In this study methacrylate-based terpolymer consisting of HMA, MMA, and MAA (20 mol $\%: 78 \mathrm{~mol} \%: 2 \mathrm{~mol} \%$ ) was successfully electrospun into well-defined oriented and random fiber architectures using an equimolar mixture of acetone and ether as the solvent. In vitro endothelial cell culture and functional analysis via cell attachment, proliferation, and viability measurements demonstrated that electrospinning significantly improved the cytocompatibility of the surfaces to endothelial cells, especially for those substrates with random fiber distribution. Endothelial cells cultured on terpolymer surfaces up to 9 days maintained their phenotype as evidenced by the heightened expression of von Willebrand factor. These results suggest that electrospun HMA:MMA:MAA terpolymer has the potential to be used in fabricating small diameter blood vessel replacements.

\section{References}

1. Lamba, NMK.; Woodhouse, KA.; Cooper, SL. Polyurethanes in Biomedical Applications. Boca Raton, FL: CRC Press LLC; 1998.

2. Boyd KL, Schmidt S, Pippert TR, Hite SA, Sharp WV. The effects of pore-size and endothelial-cell seeding upon the performance of small-diameter e-PTFE vascular grafts under controlled flow conditions. J Biomed Mater Res. 1988; 22:163-177. [PubMed: 3283132]

3. Vane JR, Anggard EE, Botting RM. Mechanisms of diseaseregulatory functions of the vascular endothelium. N Engl J Med. 1990; 323:27-36. [PubMed: 2113184]

4. Burkel WE, Graham LM, Stanley JC. Endothelial-linings in prosthetic vascular grafts. Ann N Y Acad Sci. 1987; 516:131-144. [PubMed: 2964220]

5. Lin HB, Garciaecheverria C, Asakura S, Sun W, Mosher DF, Cooper SL. Endothelial-cell adhesion on polyurethanes containing covalently attached RGD-peptides. Biomaterials. 1992; 13:905-914. [PubMed: 1477259]

6. Lin HB, Sun W, Mosher DF, Garciaecheverria C, Schaufelberger K, Lelkes PI, Cooper SL. Synthesis, surface, and cell adhesion properties of polyurethanes containing covalently grafted RGD-peptides. J Biomed Mater Res. 1994; 28:329-342. [PubMed: 8077248]

7. Lamba, NMK.; Cooper, SL. Tissue Engineering of Vascular Prosthetic Grafts. Austin, TX: R.G. Landes; 1999. Covalent grafting of RGD peptides to synthetic surfaces Zilla PGH; p. 553-559.

8. Patel HJ, Su SH, Patterson C, Nguyen KT. A combined strategy to reduce restenosis for vascular tissue engineering applications. Biotechnol Prog. 2006; 22:38-44. [PubMed: 16454490]

9. Bhat VD, Klitzman B, Koger K, Truskey GA, Reichert WM. Improving endothelial cell adhesion to vascular graft surfaces: Clinical need and strategies. J Biomater Sci Polym Ed. 1998; 9:1117-1135. [PubMed: 9860176]

10. Lannutti J, Reneker D, Ma T, Tomasko D, Farson D. Electrospinning for tissue engineering scaffolds. Mater Sci Eng C Biomimetic Supramol Syst. 2007; 27:504-509.

11. Reneker DH, Yarin AL, Zussman E, Xu H. Electrospinning of nanofibers from polymer solutions and melts. Adv Appl Mech. 2007; 41:43-195.

12. Murugan R, Ramakrishna S. Nano-featured scaffolds for tissue engineering: A review of spinning methodologies. Tissue Eng. 2006; 12:435-447. [PubMed: 16579677] 
13. Kang XH, Xie YB, Powell HM, Lee LJ, Belury MA, Lannutti JJ, Kniss DA. Adipogenesis of murine embryonic stem cells in a three-dimensional culture system using electrospun polymer scaffolds. Biomaterials. 2007; 28:450-458. [PubMed: 16997371]

14. Johnson J, Ghosh A, Lannutti J. Microstructure-property relationships in a tissue-engineering scaffold. J Appl Polym Sci. 2007; 104:2919-2927.

15. Li WJ, Laurencin CT, Caterson EJ, Tuan RS, Ko FK. Electrospun nanofibrous structure: A novel scaffold for tissue engineering. J Biomed Mater Res. 2002; 60:613-621. [PubMed: 11948520]

16. Ito Y, Hasuda H, Kamitakahara M, Ohtsuki C, Tanihara M, Kang IK, Kwon OH. A composite of hydroxyapatite with electrospun biodegradable nanofibers as a tissue engineering material. $\mathrm{J}$ Biosci Bioeng. 2005; 100:43-49. [PubMed: 16233849]

17. Chen F, Lee CN, Teoh SH. Nanofibrous modification on ultra-thin poly(epsilon-caprolactone) membrane via electrospinning. Mater Sci Eng C Biomimetic Supramol Syst. 2007; 27:325-332.

18. Ma ZW, He W, Yong T, Ramakrishna S. Grafting of gelatin on electrospun poly(caprolactone) nanofibers to improve endothelial cell spreading and proliferation and to control cell orientation. Tissue Eng. 2005; 11:1149-1158. [PubMed: 16144451]

19. Xu CY, Inai R, Kotaki M, Ramakrishna S. Aligned biodegradable nanotibrous structure: A potential scaffold for blood vessel engineering. Biomaterials. 2004; 25:877-886. [PubMed: 14609676]

20. He W, Yong T, Ma ZW, Inai R, Teo WE, Ramakrishna S. Biodegradable polymer nanofiber mesh to maintain functions of endothelial cells. Tissue Eng. 2006; 12:2457-2466. [PubMed: 16995779]

21. Nam J, Huang Y, Agarwal S, Lannutti J. Improved cellular infiltration in electrospun fiber via engineered porosity. Tissue Eng. 2007; 13:2249-2257. [PubMed: 17536926]

22. Fussell GW, Cooper SL. Synthesis and characterization of acrylic terpolymers with RGD peptides for biomedical applications. Biomaterials. 2004; 25:2971-2978. [PubMed: 14967529]

23. Fussell GW, Cooper SL. Endothelial cell adhesion on RGDcontaining methacrylate terpolymers. J Biomed Mater Res A. 2004; 70:265-273. [PubMed: 15227671]

24. Veleva AN, Khan SA, Cooper SL. Oxidative and hydrolytic stability of a novel acrylic terpolymer for biomedical applications. J Biomed Mater Res A. 2005; 74:117-123. [PubMed: 15924302]

25. Heath DE, Cooper SL. Synthesis and characterization of methacrylic terpolymer biomaterials. 2008 Submitted for publication.

26. Veleva AN, Cooper SL, Patterson C. Selection and initial characterization of novel peptide ligands that bind specifically to human blood outgrowth endothelial cells. Biotechnol Bioeng. 2007; 98:306-312. [PubMed: 17657770]

27. Veleva AN, Heath DE, Cooper SL, Patterson C. Selective endothelial cell attachment to peptidemodified terpolymers. Biomaterials. 2008; 29:3656-3661. [PubMed: 18556061]

28. Lin Y, Weisdorf D, Solovey A, Hebbel RP. Origins of circulating endothelial cells and endothelial outgrowth from blood. J Clin Invest. 2000; 105:71-77. [PubMed: 10619863]

29. Wilson CJ, Clegg RE, Leavesley DI, Pearcy MJ. Mediation of biomaterial-cell interactions by adsorbed proteins: A review. Tissue Eng. 2005; 11:1-18. [PubMed: 15738657]

30. Ruoslahti E, Pierschbacher MD. New perspectives in cell-adhesion-RGD and integrins. Science. 1987; 238:491-497. [PubMed: 2821619]

31. Giancotti FG, Ruoslahti E. Transduction-Integrin signaling. Science. 1999; 285:1028-1032. [PubMed: 10446041]

32. Inoguchi H, Tanaka T, Maehara Y, Matsuda T. The effect of gradually graded shear stress on the morphological integrity of a huvec-seeded compliant small-diameter vascular graft. Biomaterials. 2007; 28:486-495. [PubMed: 17034847] 

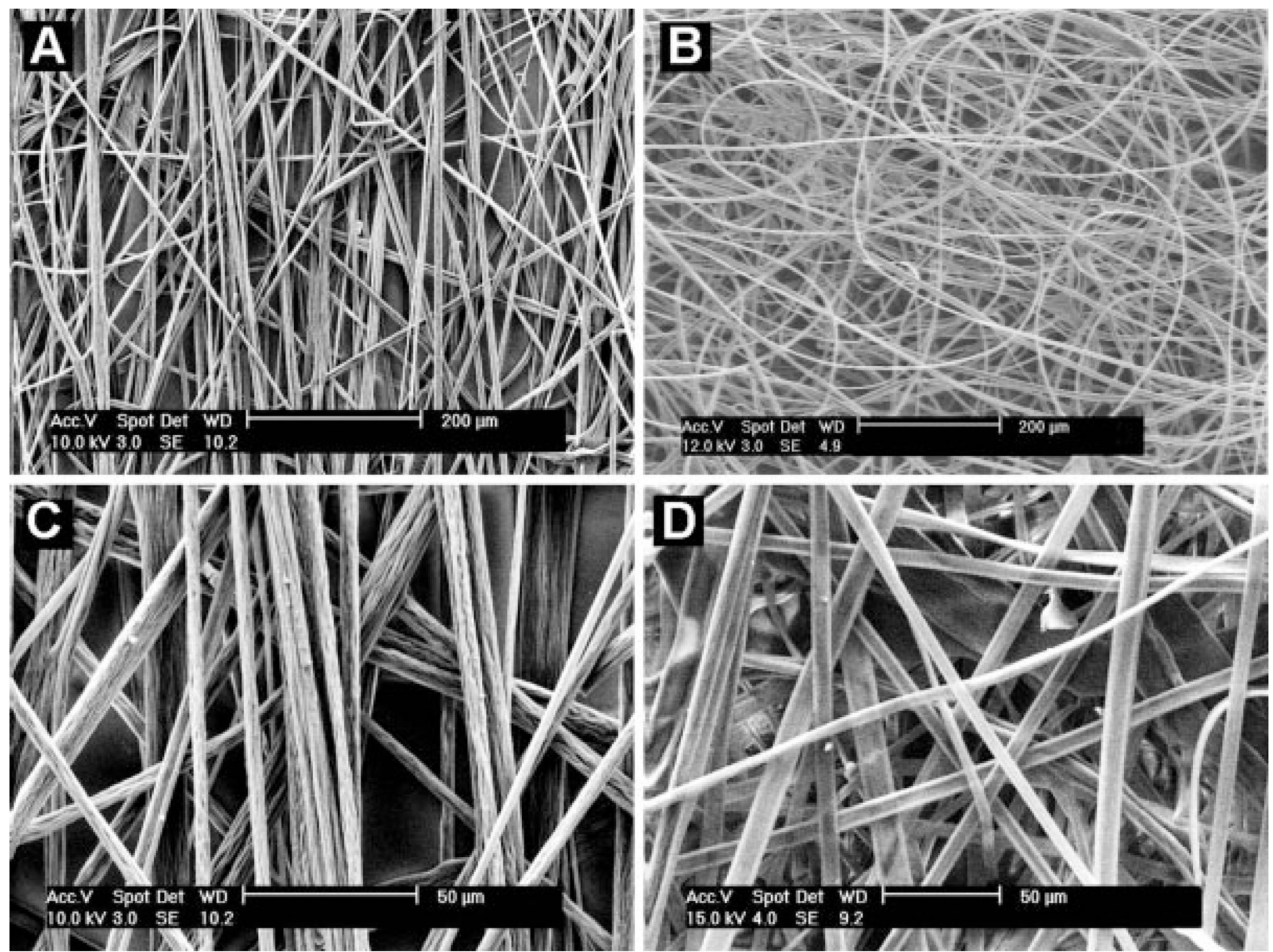

Figure 1.

SEM micrographs of electrospun HMA:MMA:MAA (20:78:2) terpolymer fibers from $13 \mathrm{w} /$ v \% acetone-ether solution (A) oriented fibers, (B) random fibers, (C) oriented fibers-high magnification, (D) random fibers-high magnification. To achieve fiber orientation, the terpolymer fibers were deposited on a rotating collector. 

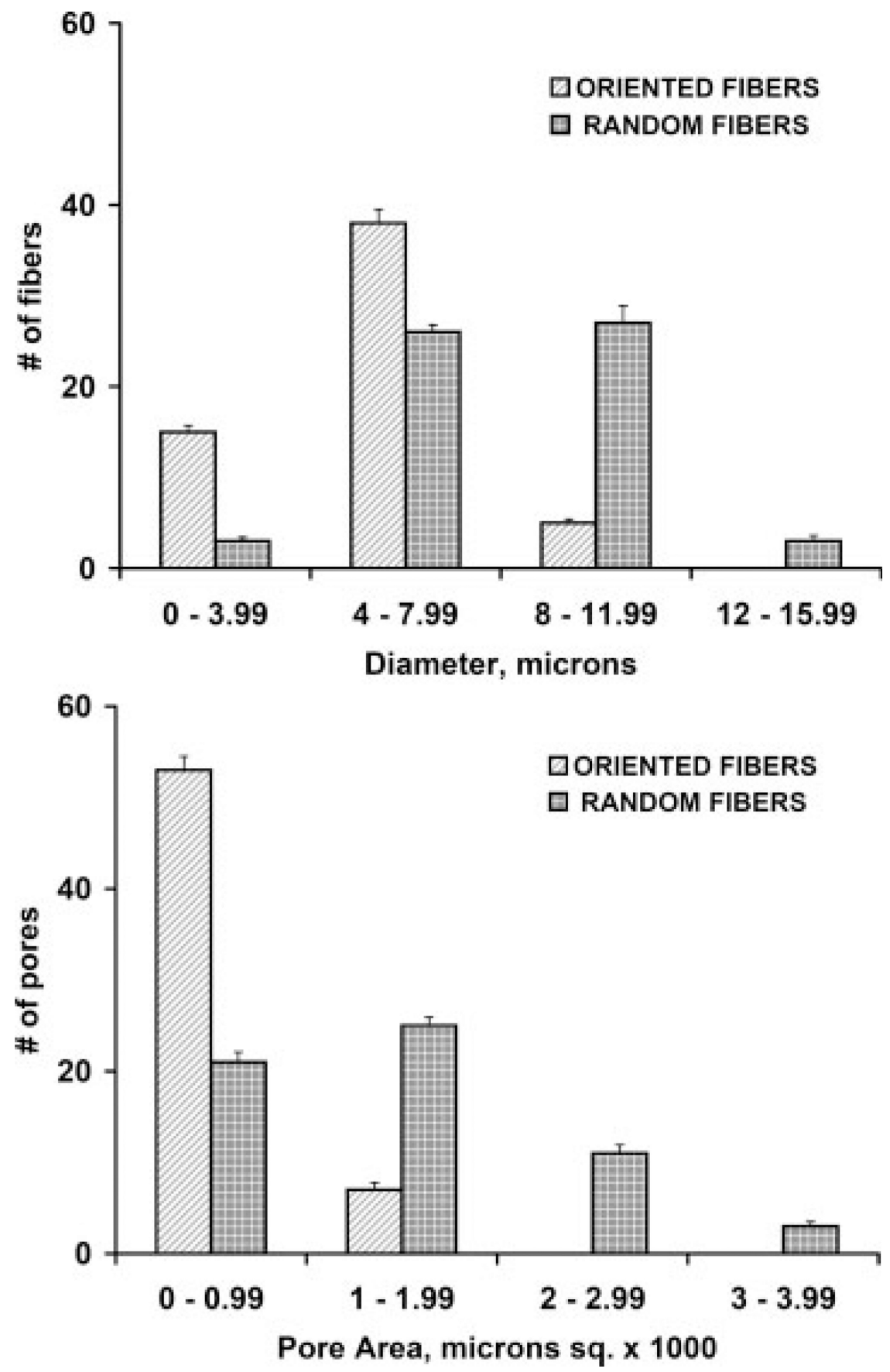

Figure 2.

Diameter distribution of the oriented and random HMA:MMA:MAA terpolymer fibers (top). Pore area distribution of the HMA:MMA:MAA fiber meshes (bottom). 


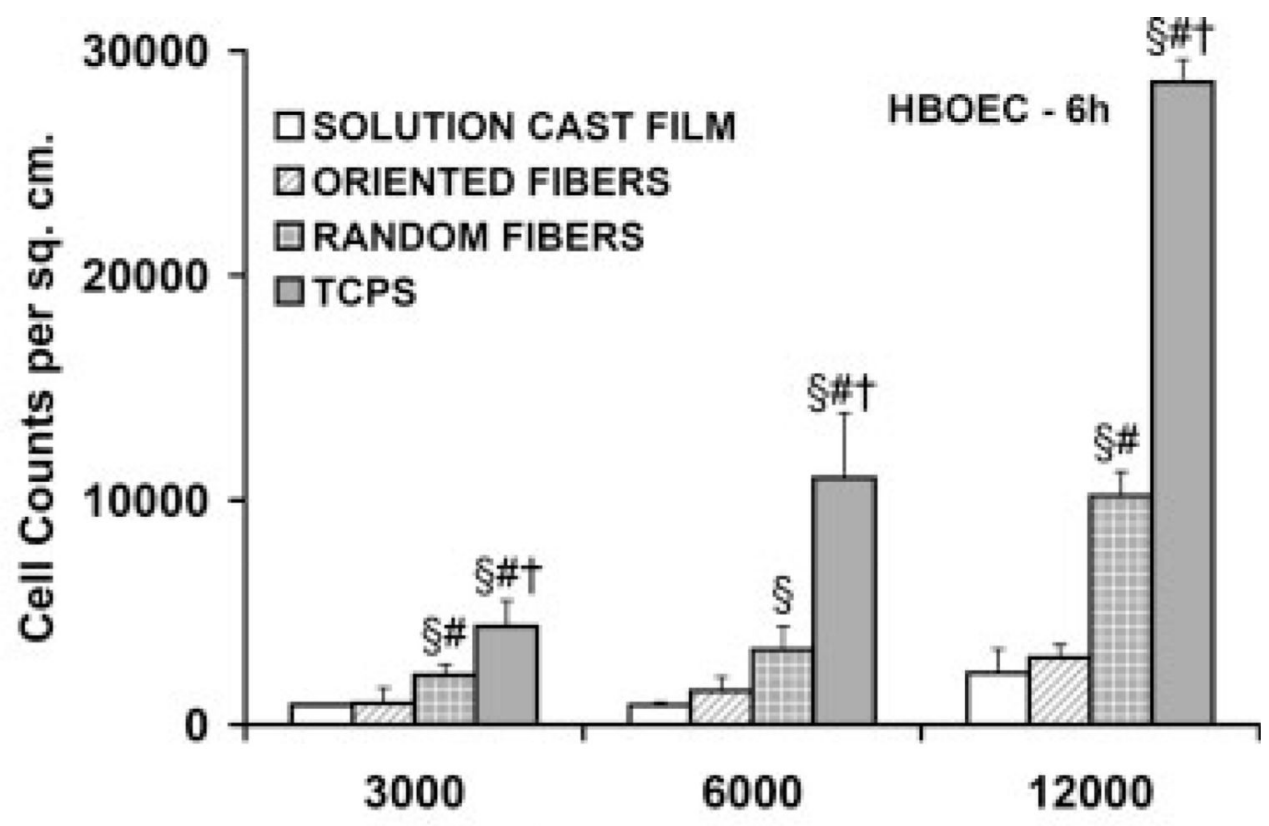

Plating Density per sq. cm.

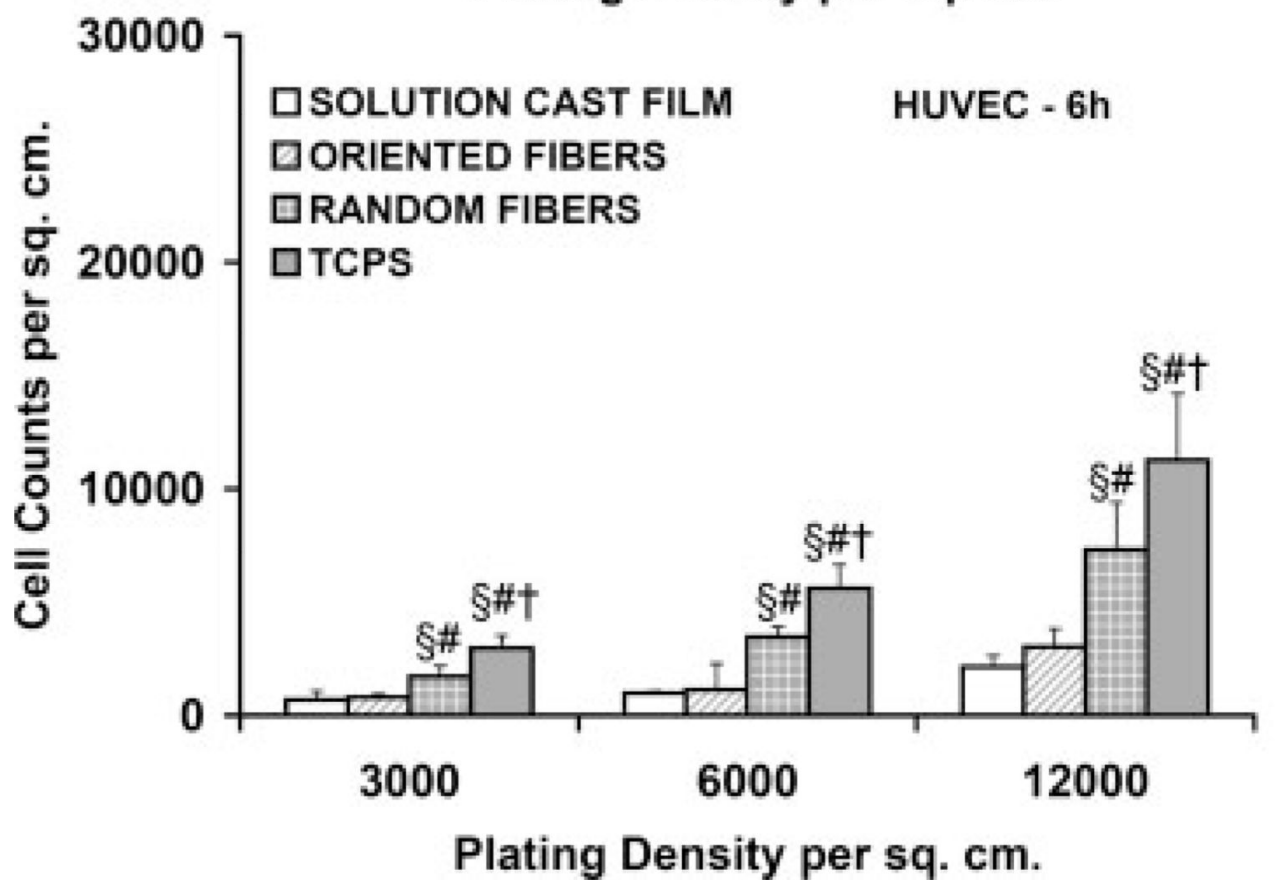

Figure 3.

Bar graph depicting cell attachment as a function of plating density for HBOEC (top) and HUVEC (bottom) after $6 \mathrm{~h}$ of cell culture on electrospun terpolymer and control surfaces. The $\S$, \#, and $\dagger$ symbols indicate statistically significant $(p<0.05)$ higher cell numbers with respect to solution cast film (§), oriented (\#), and random ( $\dagger$ ) fibers, respectively. For example, a "\# $\dagger$ " over the value bar means that condition has statistically higher attachment than either the oriented or the random fiber specimens. 

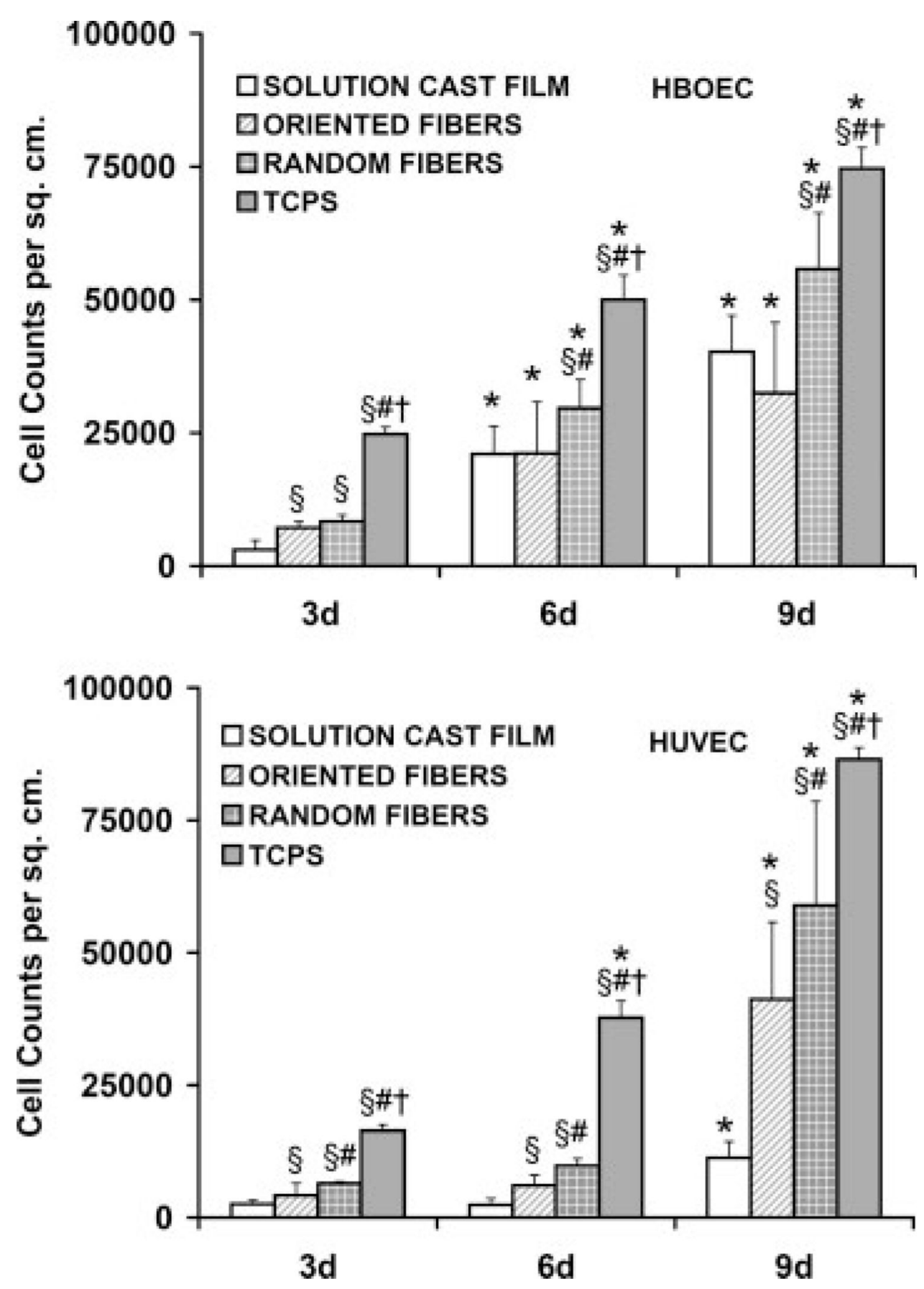

Figure 4.

Bar graph depicting cell proliferation of HBOEC (top) and HUVEC (bottom) cultured on solution cast terpolymer films, oriented fibers, random fibers, and control TCPS surfaces. The $\S$, \#, and $\dagger$ symbols have the same meaning as before however "*” is now used to indicate a significantly increased cell number with respect to preceding time point. For example, * over TCPS on day 9 in the bottom panel indicates a significantly increased cell number with respect to TCPS on day 6 . 


\section{0}

\section{$7 \square$ SOLUTION CAST FILM DORIENTED FIBERS}

Q RANDOM FIBERS

口TCPS

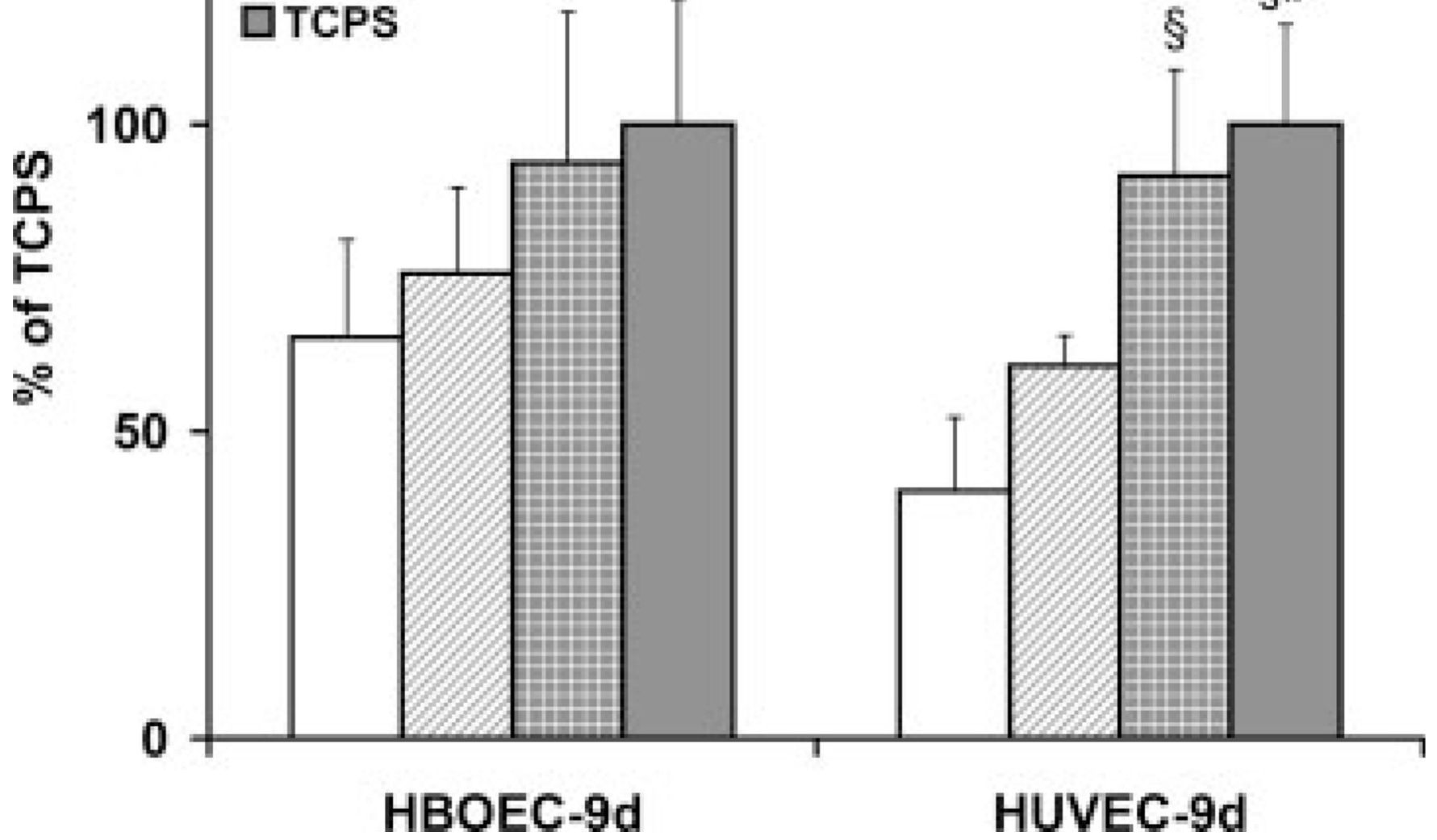

Figure 5.

Metabolic activity of HBOEC and HUVEC as measured by CCK- 8 mitochondrial activity assay after 9 days of culture on electrospun terpolymer and control surfaces. This is a direct comparison between the cells on the different surfaces without considering the varying cell numbers on each surface. The $\S$ and \# symbols indicate statistically significant $(p<0.05)$ higher overall metabolic cell activity with respect to solution cast film $(\S)$ and oriented fibers (\#). 

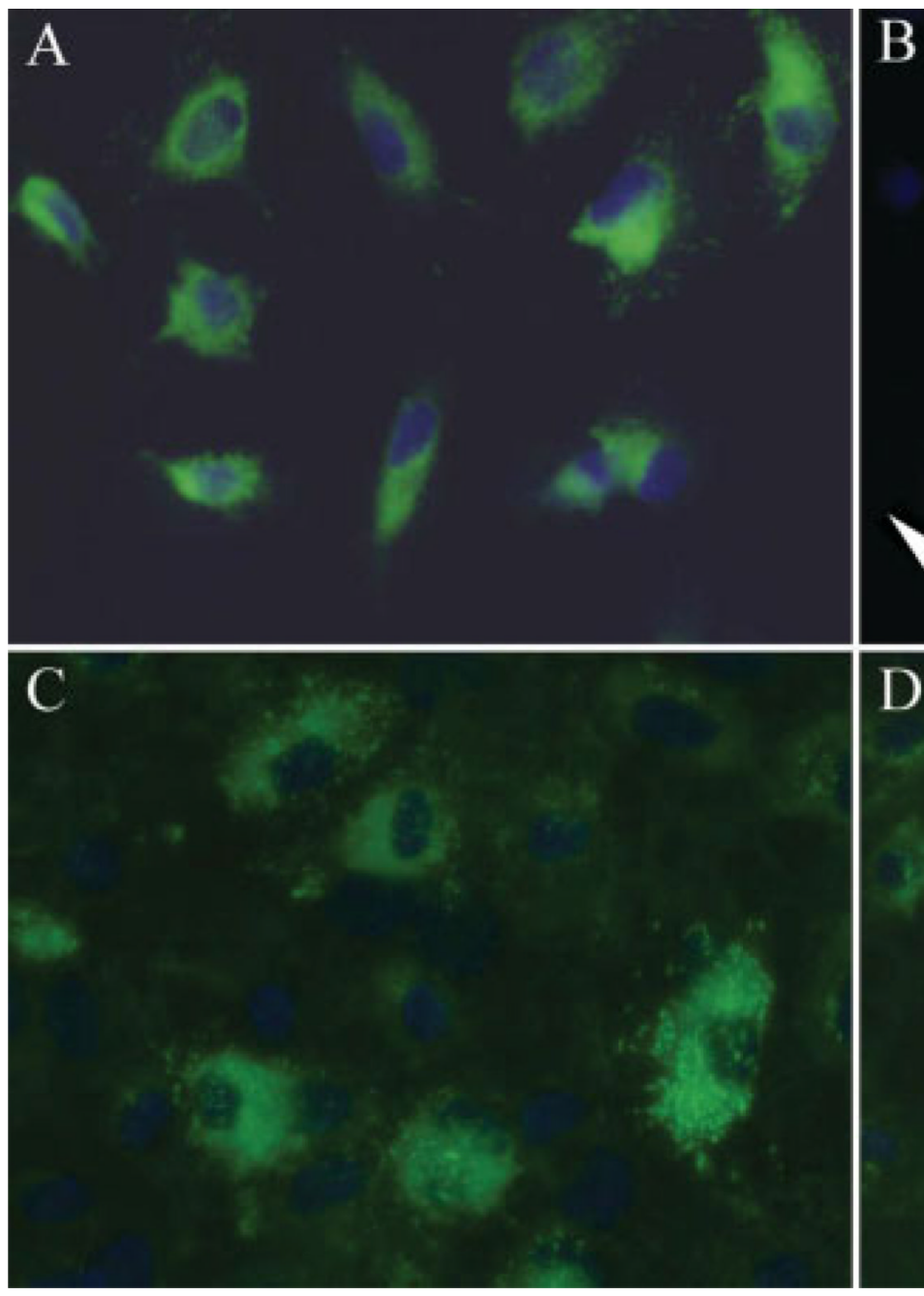

\section{D}

Figure 6.

von Willebrand factor expression and localization by HBOEC seeded on (A) solution cast films, (B) oriented fibers, (C) random fibers, (D) TCPS after 9 days of in vitro cell culture; scale bar $50 \mu \mathrm{m}$. The double arrowhead indicates the orientation of the fibers. [Color figure can be viewed in the online issue, which is available at www.interscience.wiley.com.] 